\title{
Role of Transcription Factor Nrf2 in the Induction of Hepatic Phase 2 and Antioxidative Enzymes in vivo by the Cancer Chemoprotective Agent, 3H-1, 2-Dithiole-3-thione
}

\author{
Mi-Kyoung Kwak, ${ }^{1}$ Ken Itoh, ${ }^{2}$ Masayuki Yamamoto, ${ }^{2}$ Thomas R. Sutter, ${ }^{1,3}$ and Thomas W. Kensler ${ }^{1}$ \\ ${ }^{1}$ Department of Environmental Health Sciences, Johns Hopkins School of Hygiene and Public Health, \\ Baltimore, Maryland \\ ${ }^{2}$ Institute of Basic Medical Sciences and Center for Tsukuba Advanced Research Alliance, University \\ of Tsukuba, Tennoudai, Tsukuba, Japan \\ Contributed by P. Talalay. Accepted October 16, 2000.
}

\begin{abstract}
Background: The induction of phase 2 enzymes by dithiolethiones such as oltipraz is an effective means for achieving protection against environmental carcinogens in animals and humans. Transcriptional control of the expression of at least some of these protective enzymes is mediated through the antioxidant response element (ARE) found in the upstream regulatory region of many phase 2 genes. The transcription factor Nrf2, which binds to the ARE, appears to be essential for the induction of prototypical phase 2 enzymes such as glutathione $S$-transferase (GST) Ya, Yp, and NAD(P)H: quinone reductase (NQOl) in vivo.

Materials and Methods: In the present study, 3H-1,2dithiole-3-thione (D3T) was used as a potent model inducer whose effects on gene expression and chemopreventive efficacy have been extensively characterized in the rat. Over a dozen putative D3T-inducible genes were examined in wild-type and $n r f 2$-disrupted mice by Northern blot hybridization and reverse transcriptase-polymerase chain reaction (RT-PCR) analysis to elucidate whether loss of Nrf2 function also affects the induction of a broader representation of phase 2 and antioxidative enzymes. The effects of D3T on hepatic Nrf2 expression and localization were also examined in vivo by Northern blot hybridization, electromobility shift assay, and Western blot analysis. Results: Specific activities of hepatic GST and NQO1 were increased by D3T in wild-type mice and were largely blunted in the nrf2-deficient mice. However, changes in levels of RNA transcripts following D3T treatment of $n$ rf2disrupted mice were multidirectional, dependent upon the particular gene examined. Although elevation of mRNAs for GST Ya, NQO1, microsomal epoxide hydrolase
\end{abstract}

and $\gamma$-glutamylcysteine synthetase regulatory chain were blocked in the mutant mice, elevation of GST Yp mRNA was largely unimpeded. Increases in levels of mRNA for the heavy and light chains of ferritin were only seen in the nrf2-disrupted mice. Transcript levels of UDP-glucuronyltransferase 1A6, heme oxygenase-1, maganese superoxide dismutase, which were inducible in the wild-type mice, actually decreased in the mutant mice, whereas levels of mRNA for GST Yc, aflatoxin $B_{1}$ aldehyde reductase and catalase decreased following D3T treatment in the mutant mice in the absence of any inductive effect by D3T in the wild-type mice. In wild-type mice, treatment with D3T lead to 3-fold increases in hepatic Nrf2 mRNA levels within several hours following dosing as assessed by Northern blot and RT-PCR analyses. Gel shift analyses with oligonucleotide probes for human NQOl ARE, murine GST Ya ARE, and erythroid transcription factor (NF-E2) binding site showed increased intensity of binding with nuclear extracts prepared from livers of D3Ttreated mice compared to vehicle-treated controls. Antibody to Nrf2 supershifted the DNA binding bands of these nuclear extracts. Moreover, immunoblot analysis indicated accumulation of Nrf2 in extracts prepared from hepatic nuclei of D3T-treated mice at the same time points. Conclusions: Nrf2 plays a central role in the regulation of constitutive and inducible expression of multiple phase 2 and antioxidative enzymes by chemoprotective dithiolethiones in vivo, although patterns of response vary among different genes. Knowledge of the factors controlling the specificity of actions of enzyme inducers will be exceedingly helpful in the design and isolation of more efficient and selective chemoprotective agents.

\footnotetext{
${ }^{3}$ Current address: Life Science Building, University of Memphis, Memphis, Tennessee 38152

Address correspondence and reprint requests to: Thomas. W. Kensler, Department of Environmental Health Sciences, Johns Hopkins University, School of Hygiene and Public Health, 615 N. Wolfe St., Baltimore, MD 21205. Phone: (410) 955-4712. Fax: (410) 955-0116. E-mail: tkensler@jhsph.edu

${ }^{4}$ The abbreviations used are; D3T, $3 H$-1,2-dithiole-3-thione; ARE, antioxidant response element, NF-E2, erythroid-specific
}

nuclear factor; NFE2, NF-E2 consensus sequence; GST, glutathione $S$-transferase; NQOI, NAD(P)H:quinone oxidoreductase; UGT1A6, UDP-glucuronyltransferase 1A6; $\mathrm{mEH}$, microsomal epoxide hydrolase; gGCSr, g-glutamylcyteine synthetase regulatory chain; AFAR, aflatoxin $B_{1}$ aldehyde reductase; HO-1, heme oxygenase-1; MnSOD, manganese superoxide dismutase; EMSA, electromobility shift assay; $\beta N F, \beta$-naphthoflavone; EQ, ethoxyquin; HEPES, $N$-2-hydroxyethylpiperazine- $N^{\prime}$-2-ethanesulfonic acid; PMSF, phenylmethylsulfonylfluoride 


\section{Introduction}

Dithiolethiones such as 3H-1,2-dithiole-3-thione (D3T) ${ }^{4}$ are potent chemopreventive agents that inhibit the carcinogenicity of many chemical carcinogens in multiple target organs (1-3). These broadbased protective effects of dithiolethiones have been largely associated with the induction of a battery of genes that encode phase 2 and antioxidant enzymes involved in the detoxification of exogenous and endogenous carcinogens (3). Most of these protective genes have a common cis-element, the antioxidant response element (ARE, RTGACnnnGC), in their promoters and similar sequences have been found in rat and mouse glutathione $S$-transferase (GST) Ya, rat GST Yp, rat and human NAD $(\mathrm{P}) \mathrm{H}$ quinone oxidoreductase (NQO1), mouse ferritin light chain, human $\gamma$-glutamylcysteine synthetase regulatory chain $(\gamma \mathrm{GCSr})$ and mouse heme oxygenase-1 (HO-1) (4-11). Coordinated induction of these genes by dithiolethiones and related chemopreventive agents appears to be principally regulated through the ARE (12). Because of the presence of an AP-1-like sequence (TGACTCA) in the ARE, AP-1 was suggested as an ARE-binding protein in some reports $(13,14)$. However, further studies on ARE transactivation demonstrated that rat and human NQOl ARE were not high-affinity binding sites for the JUN/FOS dimer (15-17). In addition, other novel trans-acting factors were shown to bind to the ARE in HepG2 and HeLa cells $(18,19)$. Recently, Maf and CNC-bZIP ('cap' $\mathrm{n}^{\prime}$ collar family of basic region leucine-zipper proteins) families of transcription factor have been proposed as ARE binding proteins (20). NF-E2, an erythroid-specific transcription factor is a heterodimer of $\mathrm{p} 45$, a large subunit belonging to CNC-bZIP families and small Maf subunits $(21,22)$. Nrf1, Nrf2, and Nrf3 are members of CNC-bZIP family of proteins that have strong homology to p45 (23-25) and these CNC-bZIP proteins can bind to the NF-E2 consensus sequence (TGCTGA(G/C)TCA(T/C)) found in the $\beta$-globin gene promoter region (26). The consensus sequence of NF-E2 has a high similarity to the ARE core sequence. This similarity led to the hypothesis that CNC-bZIP proteins can bind to AREs and mediate the expressions of phase 2 enzymes. In fact, the ARE of human NQO 1 can be recognized by Nrfl and Nrf2 in HepG2 cells and overexpression of these transcription factors increased the basal expression of an ARE-reporter gene and its induction by $\beta$-naphthoflavone $(\beta \mathrm{NF})$ and $t$-butylated hydroquinone (20). Moreover, elevation of GST and NQOl transcripts and proteins by the inducer butylated hydroxyanisole was largely blunted in the liver and intestine of homozygous nrf2-mutant mice (27). In a recent report, $\mathrm{HO}-1$ mRNA failed to accumulate in response to heme, cadmium and t-butylated hydroquinone in $n r f 2$ mutant L929 fibroblast cells (28). These reports collectively support the hypothesis that Nrf2 mediates the expression of at least some protective genes and may have an important function in defense mechanisms against environmental chemicals.

As a prelude to examining the effects of $n r f 2$ genotype on susceptibility to chemical carcinogens and efficacy of chemopreventive agents such as dithiolethiones, the influence of $n r f 2$ status on basal and inducible expression of a panel of hepatic carcinogen detoxification and antioxidative enzymes in vivo was determined. Moreover, the action of D3T on the expression and cellular distribution of $\mathrm{Nrf2}$ itself was investigated.

\section{Materials and Methods \\ Chemicals and Materials}

All chemicals were purchased from Sigma Chemical Co. (St. Louis, Mo) and 3H-1,2-dithiol-3-thione was provided by Dr. Thomas Curphey (Dartmouth Medical School, Hanover, NH) (29). $\left[\alpha-{ }^{32} \mathrm{P}\right] \mathrm{dCTP}$ $(3000 \mathrm{Ci} / \mathrm{mmol})$ and $\left[\gamma^{32} \mathrm{P}\right]$ ATP $(4500 \mathrm{Ci} / \mathrm{mmol})$ were purchased from ICN (Costa Mesa, Calif). cDNA probes for rat GST Ya, Yb, Yp, $\mathrm{mEH}$, chains of ferritin heavy and light and albumin were isolated in a previous study (9) and mouse GST Yc cDNA was kindly provided by Dr. David Eaton (University of Washington, Seattle, Wash) (30).

\section{Animals and Treatments}

Nrf2-disrupted ICR mice were produced as described by Itoh et al (27). Genotypes of homozygous wildtype and $n r f 2$ disrupted mice (8-12 weeks old) were confirmed by polymerase chain reaction (PCR) amplification of genomic DNA isolated from blood. PCR amplification was carried out using three different primers, 5'-TGGACGGGACTATTGAAGGCTG$3^{\prime}$ (sense for both genotypes), 5'-CGCCTTTTCAGTAGATGGAGG-3' (antisense for wild type) and 5'-GCGGATTGACCGTAATGGGATAGG-3' (antisense for LacZ). To study the effects of $n r f 2$ genotype on induction of phase 2 enzyme activities, male and female mice were fed AIN-76A diet and water ad libitum and treated by gavage with $0.3 \mathrm{mmol} / \mathrm{kg}$ of D3T in a suspension consisting of $1 \%$ Cremophor and $25 \%$ of glycerol for 3 consecutive days and sacrificed $24 \mathrm{hr}$ after the last treatment. Male mice were used in the following studies. For analyses of D3T effects on mRNA levels in wild-type and nrf2deficient genotypes, mice were treated with either vehicle or D3T $(0.5 \mathrm{mmol} / \mathrm{kg}$, p.o. $)$ and killed 6 or $24 \mathrm{hr}$ after treatment. For electromobility shift assay (EMSA), immunoblot or Nrf2 mRNA analyses, wildtype mice were sacrificed 2, 6, 24, or $48 \mathrm{hr}$ after a single treatment with D3T. Wild-type mice were also treated with $0.2 \mathrm{mmol} / \mathrm{kg}$ of $\beta \mathrm{NF}$ or $2.3 \mathrm{mmol} / \mathrm{kg}$ of EQ by gavage and hepatic levels of mRNA measured at $6 \mathrm{hr}$. 
Measurement of Enzyme Activities

Total GST activity was measured in hepatic cytosolic fractions $(105,0003 \mathrm{~g})$ using 1-chloro-2,4dinitrobenzene as substrate and NQO 1 activity measured using menadione as substrate as previously described $(31,32)$.

\section{RNA Isolation and Analysis}

Total RNA was isolated by the procedure of Chomczynski and Sacchi (33) and RNA samples were electrophoresed on $1 \%$ agarose gels containing $2.2 \mathrm{M}$ formaldehyde and transferred to nylon membranes (Schleicher and Schuell, Keene, NH). cDNAs for rat ferritin heavy and light chains, GST Ya, Yp, mEH and mouse GST Yc were labeled with $\left[\alpha-{ }^{32} \mathrm{P}\right] \mathrm{dCTP}$ using a random primer labeling kit (Amersham Pharmacia Biotech Inc., Piscataway, NJ), hybridized, and washed as described previously (34). After washing, the membranes were exposed to $\mathrm{x}$-ray film (Eastman Kodak, Rochester, NY) and developed using a Konica film processor (Shinjuku-ku, Tokyo, Japan). Labeled membranes were stripped and rehybridized with cDNA of rat albumin for normalization of loading of mRNA.
Analyses of mRNA levels of NQO1, UGT1A6, GCSr, HO-1, AFAR, MnSOD, catalase, and Nrf2 were performed using reverse transcriptase reaction. For the synthesis of CDNA, $100 \mathrm{ng}$ total RNA was incubated with $10 \mathrm{mM}$ Tris $(\mathrm{pH} \mathrm{8.4)}, 5 \mathrm{mM} \mathrm{KCl}$, $5 \mathrm{mM} \mathrm{MgCl}_{2}, 4 \mathrm{mM}$ dNTPs, $0.125 \mu \mathrm{g}$ oligo(dT) ${ }_{12-18}$, and 30 units Moloney murine leukemia virus (M-MRV) reverse transcriptase (Life Technologies, Grand Island, NY) for 15 min. PCR amplification was performed by incubating cDNA in a PCR mixture containing $10 \mathrm{mM}$ Tris $(\mathrm{pH} \mathrm{8.4)}, 5 \mathrm{mM} \mathrm{KCl}$, $1 \mathrm{mM}$ dNTPs, $2 \mathrm{mM} \mathrm{MgCl}_{2}, 120 \mathrm{nM}$ sense and antisense primers, and 1 unit Taq polymerase (Life Technologies) using a DNA thermal cycler (Perkin Elmer Applied Biosystems, Foster City, Calif). Amplification conditions were 25-30 cycles for $5 \mathrm{~min}$ at $958 \mathrm{C}, 30 \mathrm{sec}$ at $558 \mathrm{C}$ and $40 \mathrm{sec}$ at $728 \mathrm{C}$. The sense and antisense primers for PCR amplification are listed in Table 1 and were synthesized by Integrated DNA Technology (Coralville, Iowa). PCR products were electrophoresed on $0.8 \%$ agarose gels and the gel image quantified using a Un-scan-it gel image analysis program (Silk Scientific, Orem, Utah).

Table 1. Oligonucleotide sequences for PCR amplification of murine phase 2 and antioxidative enzymes and probe sequences of NFE2, mouse GST Ya ARE, and human NQO1 ARE

\begin{tabular}{|c|c|c|c|}
\hline Enzymes & & Primers & $\begin{array}{l}\text { Gene Bank } \\
\text { Accession No }\end{array}$ \\
\hline \multirow[t]{2}{*}{$\mathrm{Nrf} 2$} & Sense & ATGGATTTGATTGACATCCTT & U20532 \\
\hline & Antisense & CATGTTTTTCTTTGTATCTGG & \\
\hline \multirow[t]{2}{*}{ NQO1 } & Sense & АTCCTTCCGAGTCATCTCTA & U12961 \\
\hline & Antisense & CAACGAATCTTGAATGGAGG & \\
\hline \multirow[t]{2}{*}{ HO-1 } & Sense & AGGTGTCCAGAGAAGGCTT & X13356 \\
\hline & Antisense & ATCTTGCACCAGGCTAGCA & \\
\hline \multirow[t]{2}{*}{$\gamma \mathrm{GCSr}$} & Sense & AGGAGCTTCGGGACTGTATT & U95053 \\
\hline & Antisense & TGGGCTTCAATGTCAGGGAT & \\
\hline \multirow[t]{2}{*}{ UGT1A6 } & Sense & TGATGCTCTGTTCACAGACC & U09930 \\
\hline & Antisense & AATGCCCGAGTATTTGGATG & \\
\hline \multirow[t]{2}{*}{ AFAR } & Sense & TGCCTCAGACACTTCGGA & AW 108455 \\
\hline & Antisense & TAGTTGGGACACTCGTGG & \\
\hline \multirow[t]{2}{*}{ MnSOD } & Sense & TGAACAACCTCAACGCCAC & Z18857 \\
\hline & Antisense & GAAGGTAGTAAGCGTGCTC & \\
\hline \multirow[t]{2}{*}{ Catalase } & Sense & AACTGGGATCTTGTGGGAA & L25069 \\
\hline & Antisense & GACAGTTCACAGGTATCTG & \\
\hline \multirow[t]{2}{*}{ Albumin } & Sense & TCCATGTATGAAAAGTGCTG & AJ011080 \\
\hline & Antisense & CTGCAGCAGTCTTCTAAGAA & \\
\hline NFE2 & & TGGGGAACCTGTGCTGAGTCACTGGT & \\
\hline mGST Ya ARE & & $\begin{array}{l}\text { AGCTTGGAAATGACATTGCTAATGGTGACAA } \\
\text { AGCAACTTTGTCGAC }\end{array}$ & \\
\hline hNQO1 ARE & & GCAGTCACAGTGACTCAGCAGAATCT & \\
\hline
\end{tabular}




\section{Preparation of Hepatic Nuclear Extracts}

Nuclear extracts from murine livers were prepared according to Dignam et al (35). Briefly, snap-frozen livers were pulverized and homogenized in a lysis buffer containing $0.5 \mathrm{M}$ sucrose, $10 \mathrm{mM}$ HEPES (pH 7.9), $1.5 \mathrm{mM} \mathrm{MgCl} 2,10 \mathrm{mM} \mathrm{KCl}, 10 \%$ glycerol, 1 mM EDTA, $0.5 \mathrm{mM}$ dithiothreitol, and $1 \mathrm{mM}$ PMSF using a Dounce homogenizer. Crude nuclear fractions were collected by centrifugation and extracted for 30 min using extraction buffer containing $20 \mathrm{mM}$ HEPES (pH 7.9), $1.5 \mathrm{mM} \mathrm{MgCl} 2,420 \mathrm{mM} \mathrm{NaCl}, 10 \%$ glycerol, $0.2 \mathrm{mM}$ EDTA, and $0.5 \mathrm{mM}$ PMSF. Protein concentration was determined by the bicinchoninic acid protein assay (Pierce Inc., Rockford, Ill).

\section{Electrophoretic Mobility Shift and Supershift Analyses}

NF-E2 consensus binding sequence, human NQO1 ARE, or mouse GST Ya ARE (Table 1) were endlabeled with $\left[\gamma^{-32} \mathrm{P}\right]$ ATP and incubated with $5 \mu \mathrm{g}$ hepatic nuclear extracts for $30 \mathrm{~min}$ at room temperature in a reaction mixture containing $10 \mathrm{mM}$ HEPES (pH 7.9), $60 \mathrm{mM} \mathrm{KCl}, 0.5 \mathrm{mM}$ EDTA, 4\% Ficoll, $1 \mathrm{mM}$ PMSF, and $0.2 \mu \mathrm{g}$ poly (dI-dC). For supershift analyses, $1 \mu \mathrm{g}$ Nrf2 antibody (Santa-Cruz, Santa Cruz, Calif) was incubated with the reaction mixture for $\mathrm{l} \mathrm{hr}$. Loading buffer was added and the reaction products were analyzed on a $4 \%$ acrylamide gel (80:1::acrylamide:bisacrylamide) and exposed to $\mathrm{x}$-ray film for $16 \mathrm{hr}$.

\section{SDS PAGE and Immunoblot Analysis of Nrf2 Levels}

Hepatic nuclear extracts and cytosolic fractions $(105,0003 \mathrm{~g})$ were isolated from liver homogenates and SDS polyacrylamide gel electrophoresis was performed by loading either $25 \mu \mathrm{g}$ nuclear extract, $35 \mu \mathrm{g}$ cytosolic or total homogenate protein on a $6 \%$
SDS-polyacrylamide gel. Following separation, gels were transferred to nitrocellulose membranes (Amersham Pharmacia Biotech. Inc.) at $40 \mathrm{~V}$ for $18 \mathrm{hr}$ and immunoblotting was carried out using two kinds of Nrf2 antibodies. A commercial antibody (Santa-Cruz) reacts with the carboxyl amino terminal of mouse Nrf2 while a second antibody reacts with the amino terminal (Itoh and Yamamoto, unpublished observations). Immunoblotted membranes were developed using the ECL Western blotting system (Amersham Pharmacia Biotech. Inc.) according to the manufacturer's instructions.

\section{Statistical Analyses}

Statistical significance was determined by one- or two-way ANOVA followed by Student-NewmanKeuls's multiple comparison method.

\section{Results \\ Effect of Gender, nrf2 Genotype, and D3T on Phase 2 Enzyme Activities and Gene Expression}

GST and NQOI activities were measured in hepatic cytosolic fractions prepared from male and female, vehicle- or D3T-pretreated, wild-type and $n r f 2$-disrupted mice. Hepatic GST activity was 2 -fold higher in male mice than female mice irrespective of $n r f 2$ genotype (Fig. 1). However, specific activities were $50 \%$ lower in $n r f 2$ mutant mice. GST activity was increased 1.4-fold and 5 -fold in male and female wild-type mice, respectively, by D3T treatment. Induction of GST activity was almost entirely abrogated in both male and female nrf2-disrupted mice. NQOI activity was increased 3-fold in wild-type mice of either gender by D3T, although females had a nearly 3-fold higher basal activity than males. Induction of
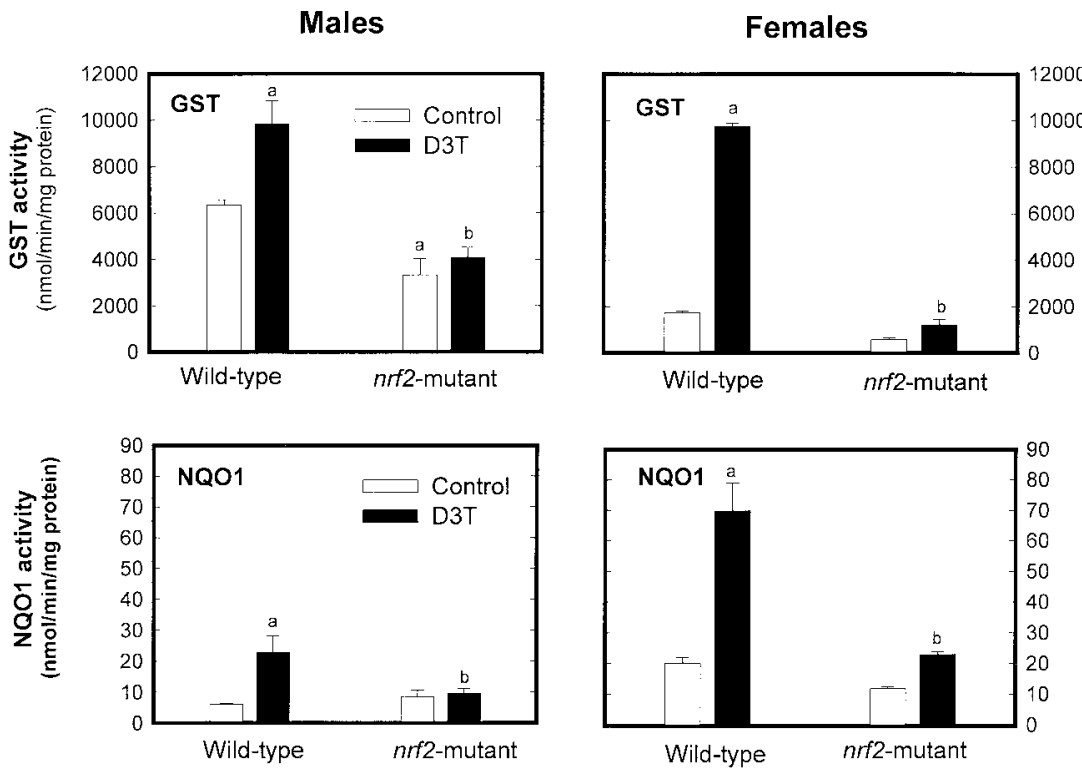

Fig. 1. Effect of $n r f 2$ genotype and gender on hepatic activities of GST and NQOI by D3T. GST (CDNB) and NQOI (menadione) activities were measured in hepatic cytosols prepared from wild-type and nrf2-disrupted mice pretreated with D3T $(0.3 \mathrm{mmol} / \mathrm{kg}$ p.o. $)$ for 3 consecutive days. Mice were killed $24 \mathrm{hr}$ after the last dose of D3T. (a) $p, 0.05$ compared to wild-type vehicle treated control. (b) $p, 0.05$ compared to wild-type mice treated with D3T. Values are mean 6 SEM for three animals in each group. 
NQO1 activity was not detected in male nrf2disrupted mice, and induction was only partially attenuated in female $n r f 2$-disrupted mice. Although superimposed on large gender effects on GST and NQO1 activities, loss of expression of Nrf2 in the mutant mice suppressed both basal and inducible activities of these enzymes.

To investigate the role of Nrf2 on the expression of a broader range of D3T-inducible genes, male wild-type and nrf2-disrupted mice were dosed with $0.5 \mathrm{mmol} / \mathrm{kg} \mathrm{D} 3 \mathrm{~T}$ and hepatic levels of mRNA for GST Ya, Yb, Yc and Yp, NQOl, mEH, UGTIA6, GCSr, AFAR, ferritin heavy and light chains, HO-1, MnSOD and catalase were measured 6 or $24 \mathrm{~h}$ later (Table 2). All of these genes have been shown to be inducible by $\mathrm{D} 3 \mathrm{~T}$ in rat liver $(9,36)$. In male wildtype mice, hepatic levels of mRNA for GST Ya, Yb, Yp, mEH, NQOl, UGTIA6, GCSr, and MnSOD mRNA were significantly increased by 6.4-, 2.6-,

Table 2. Effects of $n r f 2$ genotype on changes in mRNA levels of phase 2 and antioxidative enzymes following treatment with D3T

\begin{tabular}{|c|c|c|c|c|}
\hline \multirow{3}{*}{$\begin{array}{l}\frac{\text { Nrf2 Genotype }}{\text { Enzyme }} \\
\text { GST Ya }\end{array}$} & $+/+$ & $-1-$ & $+/+$ & $-/-$ \\
\hline & \multicolumn{2}{|c|}{$\begin{array}{c}\text { Constitutive } \\
\text { Levels }\end{array}$} & \multicolumn{2}{|c|}{$\begin{array}{l}\text { Inducible } \\
\text { Levels }\end{array}$} \\
\hline & 1 & 0.63 & $6.38^{a}$ & 0.79 \\
\hline GST Yp & 1 & 0.28 & $4.93^{a}$ & $0.66^{b}$ \\
\hline GST Yb & 1 & 1.26 & $2.63^{a}$ & 0.87 \\
\hline GST Yc & 1 & 0.75 & 1.07 & $0.29^{b}$ \\
\hline NQOl & 1 & 1.11 & $5.95^{a}$ & 0.67 \\
\hline UGT1A 6 & 1 & 0.99 & $3.63^{a}$ & $0.24^{b}$ \\
\hline $\mathrm{mEH}$ & 1 & 0.52 & $4.02^{a}$ & 1.13 \\
\hline$\gamma \mathrm{GCSr}$ & 1 & 1.29 & $2.84^{a}$ & 1.40 \\
\hline AFAR & 1 & 0.73 & 1.13 & $0.15^{b}$ \\
\hline HO-1 & 1 & 1.66 & $5.89^{a}$ & 0.72 \\
\hline Ferritin Light & 1 & 0.94 & 1.53 & $2.45^{b}$ \\
\hline Ferritin Heavy & 1 & 0.58 & 1.13 & $2.08^{b}$ \\
\hline MnSOD & 1 & 1.31 & $2.02^{a}$ & $0.05^{b}$ \\
\hline Catalase & 1 & 1.08 & 1.40 & $0.39^{b}$ \\
\hline
\end{tabular}

Relative mRNA levels were analyzed after D3T treatment in $n r f 2$ wild-type and mutant type mouse liver. GST Ya, Yp, Yb, Yc, $\mathrm{mEH}, \mathrm{FH}$, and FL mRNA were detected using northern blot hybridization and NQO1, UGT1A6, $\gamma$ GCSr, HO-1, AFAR, MnSOD, and CAT levels were detected using RT-PCR. Values are the means of determinations done on three mice per genotype. Levels of RNA for each gene were normliazed to albumin mRNA levels and expressed as a ratio over vehicletreated wild-type control. Transcript levels were measured $24 \mathrm{hr}$ after treatment with D3T for all genes except HO-l, which was measured at $6 \mathrm{hr}$.

${ }^{a} p, 0.05$, compared to vehicle-treated $2 / 1$.

${ }^{b} p, 0.05$, compared to vehicle-treated $2 / 2$ group.
4.9-, 4.0-, 6.0-, 3.6-, 2.8-, and 2.0-fold following D3T treatment compared with vehicle-treated, wild-type mice, while mRNA levels of GST Yc, ferritin heavy chain, ferritin light chain, AFAR, and catalase remained unchanged. Murine GST Yc is a homologue of rat GST Yc2 that is readily induced by butylated hydroxyanisole and oltipraz in this species (37). AFAR reduces aflatoxin $B_{1}$ aldehyde to a nontoxic dialcohol and can also be highly induced by $\mathrm{D} 3 \mathrm{~T}$ in rat liver (38). The high constitutive levels of expression of GST Yc in mice (data not shown) may account for the striking difference in sensitivity of mice and rats to some toxicants (39).

Both constitutive and inducible expression of these genes was affected by nrf2-disruption in vivo, although no single pattern of response encompassed all genes. Vehicle-treated male nrf2-disrupted mice showed lower mRNA levels for GST Ya, Yp, Yc, NQO1, $\mathrm{mEH}$, and ferritin heavy chain than vehicletreated wild-type mice. Most of the D3T-inducible genes of wild-type mice had a poor responsiveness toward D3T in livers of $n r f 2$-disrupted mice. For example, induction of GST Ya mRNA by D3T was only $25 \%$ in $n r f 2$-disrupted mice liver compared to $600 \%$ in wild-type mice. In the mutant mice, GST Yp mRNA level was doubled after D3T treatment compared to a 5-fold induction of GST Yp in wild-type mice. GST Yb, NQO1, mEH, GCSr, and HO-l also showed minimal inducibility by D3T in the mutant as opposed to wild-type mice. Some genes retained the inducibility by D3T in the absence of Nrf2. Ferritin heavy and light chain mRNA levels were increased after dosing with D3T in nrf2-disrupted mice. In yet another outcome, several genes (e.g., GST Yc, UGTIA6, AFAR, MnSOD, and catalase), which with the exception of UGTIA6 were not inducible in wild type mice, showed significant reduction in steady state mRNA levels in nrf2-disrupted mice following D3T treatment. Collectively, these results demonstrate that $\mathrm{Nrf} 2$ is an essential factor in the up-regulation of many, but not all, phase 2 and antioxidant enzymes induced by D3T, and that disruption of this gene greatly alters the constitutive and inducible expression of most of these genes.

Effects of D3T on DNA Binding Activity of Nrf2 to NF-E2 Consensus Sequence (NFE2), mGST Ya, and hNQO1 AREs

Because of the apparent central role of Nrf2 in induction of many phase 2 and antioxidative enzymes in vivo, EMSA were performed using nuclear extracts isolated from livers of wild-type mice to determine whether D3T influenced the binding of Nrf2 to DNA. NFE2, mouse GST Ya ARE, and human NQO1 ARE sequences were used as binding probes to assess the DNA binding activity of Nrf2. NFE2 is an NF-E2related factor-binding site that is found in the $\beta$-globin promoter region and is recognized by Nrf2. Nuclear extracts prepared from livers of wild-type mice 2, 6, 24, and $48 \mathrm{hr}$ after dosing with D3T showed increased NFE2 binding activity compared to 
A
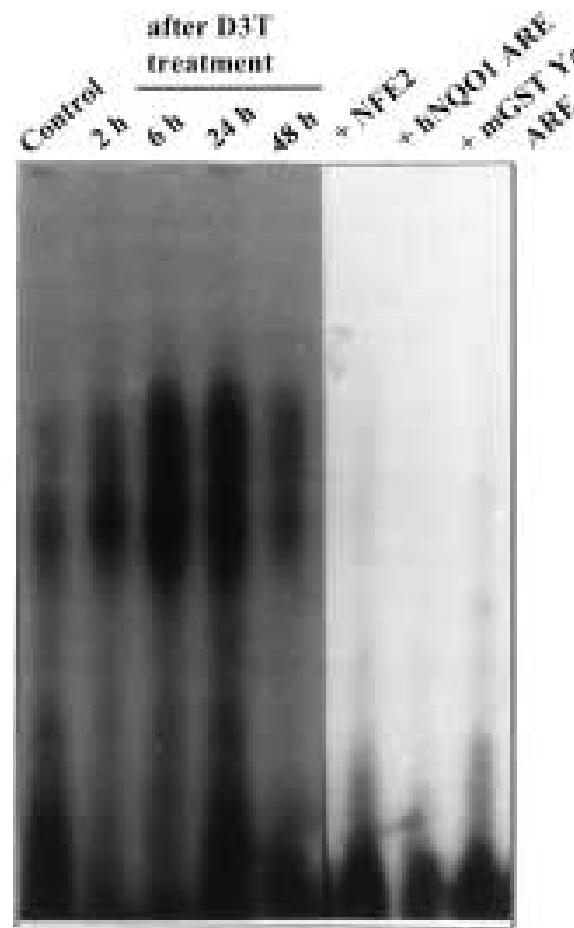

Fig. 2. Electromobility shift and supershift assays of NFE2 and AREs. Nuclear extracts were prepared from livers of wildtype mice at the indicated time points after dosing with D3T. Synthetic NFE2 and AREs from mGST Ya and hNQOl were endlabeled and incubated with $5 \mu \mathrm{g}$ nuclear extract protein. (A) Electromobility shift assays of NFE2 with hepatic nuclear extract isolated 2, 6, 24, and $48 \mathrm{hr}$ after treatment with D3T $(0.5 \mathrm{mmol} / \mathrm{kg})$ or $6 \mathrm{hr}$ after vehicle. Competitive binding assays were performed by adding 100-fold excess cold NFE2, hNQO1 and mGST Ya AREs to the reaction mixture containing nuclear extract isolated $48 \mathrm{hr}$ after treatment. (B) Electromobility supershift assays of NFE2 and AREs from mGST Ya and hNQOl. Antibody reacting with the C-terminal of Nrf2 was incubated with DNA and nuclear extracts for $1 \mathrm{hr}$ and then analyzed on $4 \%$ acrylamide gels. Nuclear extracts were prepared from four pooled livers and three supershift assays were performed with each DNA probe.

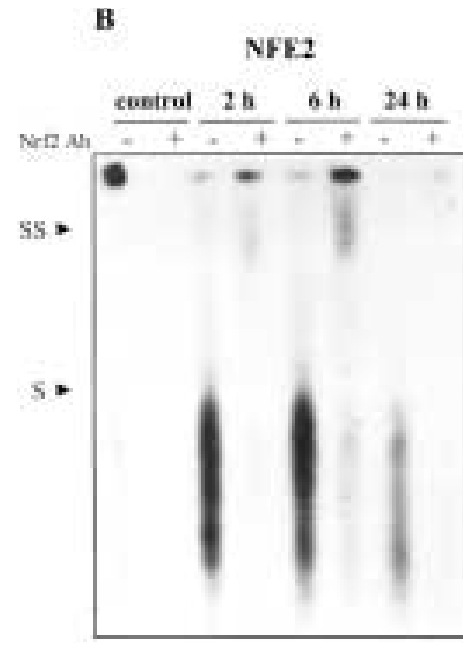

hNQOI ARE.

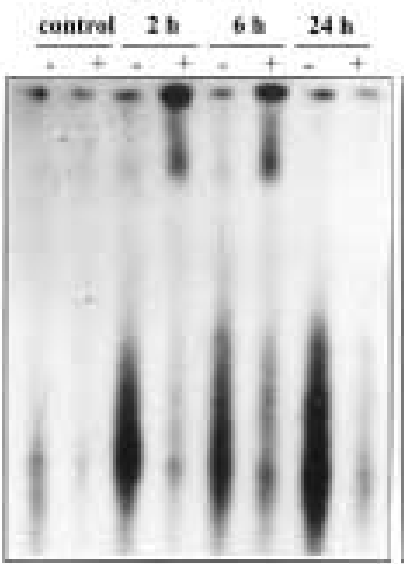

extracts prepared from vehicle-treated controls (Fig. 2A). The intensity of the shifted protein-DNA band $48 \mathrm{hr}$ after treatment was competitively inhibited by addition of cold NFE2 to the reaction mixture; these bands were also inhibited with addition of cold AREs of mGST Ya and hNQOl (Fig. 2A). These results suggest that the proteins bound to NFE2 also bind to mGST Ya and hNQOl ARE to an equivalent extent. When hNQOl ARE was used as the binding probe, a similar binding pattern was observed as for NFE2, while, in case of mGST Ya ARE, multiple binding bands appeared in the gel. These major binding bands were also inhibited by excess cold NFE2 (data not shown). Nuclear extracts isolated from D3Ttreated mice had a much higher binding activity toward mGST Ya and hNQO 1 AREs at 2, 6, and $24 \mathrm{hr}$ after treatment compared to extracts prepared from vehicle-treated mice (data not shown). Supershift assays were carried out by adding Nrf2 antibody to the reaction mixtures to clarify the role of $\mathrm{Nrf} 2$ in the observed increase in binding activity of nuclear extracts to NFE2 or the two ARE sequences. Nrf2 antibody (1 $\mu \mathrm{g}$ ) reacting with the C-terminal of $\mathrm{Nrf} 2$ was incubated for $1 \mathrm{hr}$ with $5 \mu \mathrm{g}$ nuclear extracts. Nuclear protein-DNA bands from extracts prepared 2 and $6 \mathrm{hr}$ after dosing with D3T were supershifted with NFE2 as well as mGST Ya and hNQOl AREs (Fig. 2B). These data suggest that nuclear binding activity of Nrf2 was increased by D3T treatment in vivo and that activation is an early response to this inducer. 
Supershifted bands disappeared $24 \mathrm{hr}$ after treatment despite a residual binding activity seen with EMSA at $24 \mathrm{hr}$ with AREs. This result indicates that other proteins either elevated or activated by D3T at later time points can also bind to AREs. Collectively, these results are consistent with the hypothesis that increased binding activity of Nrf2 toward ARE may have a primary but not unilateral role in the induction of some phase 2 and antioxidative enzymes in vivo.

\section{Effects of D3T on the Levels of Nrf2 Protein in Different Cellular Fractions}

Levels of Nrf2 protein were examined in various fractions of livers of wild-type mice at several time points following D3T treatment. Total homogenates, nuclear extracts, and cytosolic fractions were obtained and subjected to immunoblot analysis. Extracts of 293 T cells overexpressing mouse Nrf2 were used as a positive control for immunoblot analysis. The coding region of Nrf2 cDNA is about $1700 \mathrm{bp}$, so the predicted size of $\mathrm{Nrf} 2$ is $72 \mathrm{kD}$. However, as reported previously, Nrf2 protein migrates slowly and the approximate size is $100 \mathrm{kD}$ on a $6 \%$ SDS gel (24). Nrf2 protein was barely detected in hepatic nuclear extracts at any time after vehicle treatment, but Nrf2 levels were increased 4-fold at $2 \mathrm{hr}$ and 3 -fold at $6 \mathrm{hr}$ after treatment with D3T (Fig. 3A). In accord with the supershift analysis, Nrf2 protein decreased to near control levels $24 \mathrm{hr}$ after treatment with D3T.

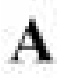

\section{Nuclear Extract}

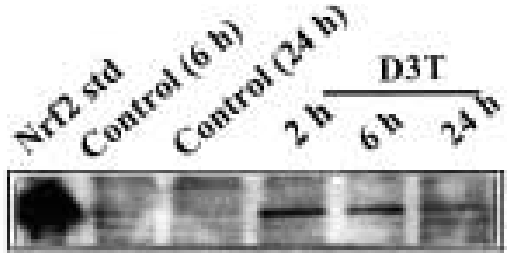

B

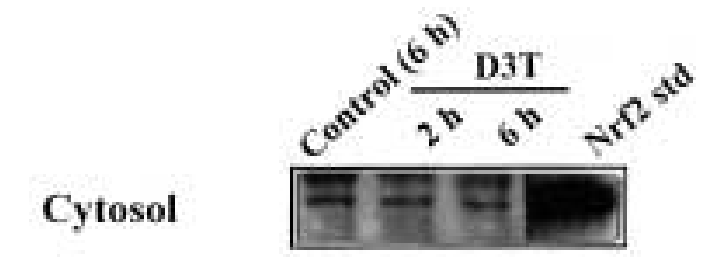

Homogenate

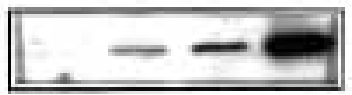

Fig. 3. Hepatic Nrf2 protein levels after treatment with D3T. Hepatic nuclear extract (A), cytosolic, and total homogenate fractions (B) were prepared from livers of wild-type mice and electrophoresed on a $6 \%$ acrylamide gel. Immunoblot analysis was carried out using Nrf2 antibody reacting with the $\mathrm{N}$-terminal of Nrf2. Each sample was prepared from four pooled livers at 2, 6, and $24 \mathrm{hr}$ after treatment with D3T $(0.5 \mathrm{mmol} / \mathrm{kg}$ p.o.) or $6 \mathrm{hr}$ after vehicle treatment. Three similar immunoblots were obtained.
Nrf2 levels in total hepatic homogenates and cytosolic fractions were also examined (Fig. 3B). After longer exposures of the immunoblots, Nrf2 protein could be detected in homogenate and cytosolic fractions. There was an increase in the levels of Nrf2 protein in total homogenates prepared 2 and $6 \mathrm{hr}$ after treatment with D3T compared to vehicle-treated mice, but no change in the levels of Nrf2 within cytosol. These results suggested that de novo protein synthesis of Nrf2 might be involved, because overall hepatic content of Nrf2 appeared to increase following D3T treatment.

\section{Effect of D3T on Hepatic Levels of Nrf2 mRNA}

Hepatic levels of Nrf2 mRNA were measured in male wild-type mice after D3T treatment to determine whether enhanced transcription/translation of $n r f 2$ could contribute to the increased levels of Nrf2 in nuclear extracts and total homogenates. Primers for amplifying the coding region of $n r f 2$ were used to obtain a mouse Nrf2 cDNA. PCR using mouse cDNA produced from total hepatic RNA of wildtype mice generated $1.7 \mathrm{~kb}$ of $\mathrm{Nrf} 2$ cDNA. This cDNA was used as a template for random primer labeling and Northern blot hybridizations. Steadystate levels of Nrf2 mRNA increased 3.3-fold $6 \mathrm{hr}$ following a single dose of D3T (Fig. 4A). An increase in mRNA level was also detected $2 \mathrm{hr}$ after
$\mathbf{A}$

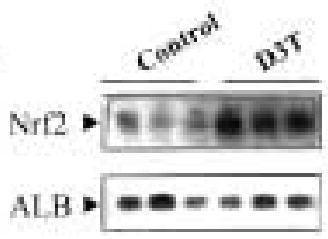

B

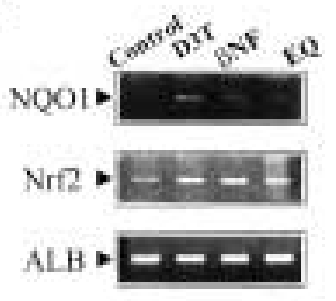

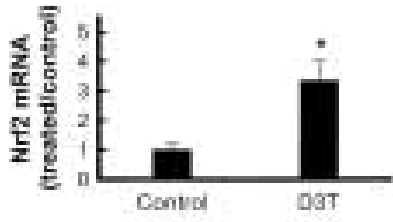

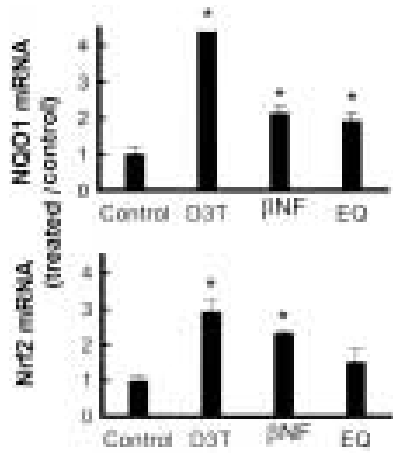

Fig. 4. Hepatic Nrf2 mRNA levels after treatment with D3T. Total RNA was prepared from three individual livers of wild type mice $6 \mathrm{hr}$ after dosing with D3T (0.5 mmol/kg p.o.), $\beta \mathrm{NF}(0.2 \mathrm{mmol} / \mathrm{kg}$ p.o. $)$ or EQ $(2.3 \mathrm{mmol} / \mathrm{kg}$ p.o. $)$ and used for RT-PCR analysis and northern blot hybridization. (A) Northern blot hybridization analysis of Nrf2 and albumin mRNA. Levels of Nrf2 mRNA were normalized against albumin and expressed as a ratio of treated over control. (B) Representative RT-PCR analysis of NQO1, Nrf2, and albumin mRNA in livers isolated $6 \mathrm{~h}$ after pretreatment of mice with vehicle, D3T, $\beta \mathrm{NF}$, or EQ. Histograms are mean 6 SEM of mRNA levels in three animals. (*) $p, 0.05$ compared to vehicle control. 
treatment (3.8-fold). Nrf2 mRNA levels declined to control levels within $24 \mathrm{hr}$ after treatment (data not shown). Other inducers also elevated steady-state levels of Nrf2 mRNA at the $6 \mathrm{hr}$ time point. Interestingly, comparable increases in mRNA levels of Nrf2 and NQO1 were seen following treatment with $\beta N F$ and EQ (Fig. 4B). NQO1 and Nrf2 mRNAs were increased 2 -fold by a dose of $0.2 \mathrm{mmol} / \mathrm{kg}$ of $\beta \mathrm{NF}$, while treatment with $2.3 \mathrm{mmol} / \mathrm{kg}$ of $\mathrm{EQ}$ induced NQO1 mRNA levels 1.9-fold and Nrf2 mRNA 1.5-fold. Elevation of NQO1 and Nrf2 levels were 5-fold and 3-fold, respectively, $6 \mathrm{hr}$ after treatment with $0.5 \mathrm{mmol} / \mathrm{kg}$ of D3T. These results indicate that not only D3T, but also other chemoprotective phase 2 inducers, can increase the level of Nrf2 mRNA in vivo.

\section{Discussion}

Gene-disrupted animals provide elegant models for assessing the molecular mechanisms underlying the pharmacodynamic actions of chemopreventive agents. The present study confirms that mice lacking the transcription factor Nrf2 lose their inducibility of some phase 2 enzymes, but also establishes that this pattern of response is not universal. In a preliminary study, elevations in the protein levels for GST subunits $\mathrm{Ya}_{1}, \mathrm{Ya}_{3}, \mathrm{Yb}$, and $\mathrm{Yp}$ as well as mRNA transcript for NQO1 seen in wild-type mice following feeding of BHA were absent in nrf2-disrupted mice (27), suggesting that $\mathrm{Nrf} 2$ was critical in the molecular signaling for induction of these phase 2 enzymes. In the present study, D3T was used as a potent model inducer whose effects on gene expression and chemopreventive efficacy had been extensively characterized in the rat $(9,36)$. Thus, over a dozen putative D3T-inducible genes were examined in wild-type and $n r f 2$-disrupted mice to elucidate whether loss of Nrf2 function also affects the induction of a broader representation of phase 2 and antioxidative enzymes. As expected, specific activities of hepatic GST and NQO I were increased by D3T in wild-type mice and were largely blunted in the nrf2-deficient mice. However, as summarized in Table 3, changes in levels of RNA transcripts following D3T treatment of $n r f 2$-disrupted mice were multidirectional, depending on the particular gene examined. Although induction of GST Ya, NQO1, $\mathrm{mEH}$, and $\gamma \mathrm{GCSr}$ was blocked in the nrf2disrupted mice, induction of GST Yp was largely unimpeded. Induction of the heavy and light chains of ferritin was only seen in the nrf2-disrupted mice. Transcript levels of UGT1A6, HO-1, MnSOD, which were inducible in the wild-type mice, actually decreased in the mutant mice, and levels of mRNA for GST Yc, AFAR, and catalase decreased following D3T treatment in the mutant mice in the absence of any inductive effect by D3T in the wild-type mice. Nonetheless, despite these varied responses, the presence or absence of Nrf2 influenced the expression of all genes examined, save albumin, following D3T treatment.
Table 3. Summary of the effects of D3T on the induction of hepatic murine genes in wild-type and nrf2-disrupted mice

\begin{tabular}{|c|c|c|c|}
\hline & \multicolumn{2}{|c|}{ Genotype } & \multirow[b]{2}{*}{ Examples } \\
\hline & $+/+$ & $-1-$ & \\
\hline $\begin{array}{l}\mathrm{O} \\
\mathrm{U}\end{array}$ & $\uparrow$ & - & GST Ya, QR, mEH, $\gamma \mathrm{GCSr}$ \\
\hline $\mathrm{T}$ & $\uparrow$ & $\uparrow$ & GST Yp \\
\hline $\mathrm{C}$ & $\uparrow$ & $\downarrow$ & UGT1A6, HQ1, MnSOD \\
\hline $\mathrm{O}$ & - & $\uparrow$ & Ferritin $\mathrm{H}$ \& L \\
\hline $\begin{array}{l}M \\
\mathrm{E}\end{array}$ & - & $\downarrow$ & GST Yc, AFAR, catalase \\
\hline S & - & - & Albumin \\
\hline
\end{tabular}

The observation that $\mathrm{D} 3 \mathrm{~T}$ reduced the expression level of certain phase 2 genes in $n r f 2$-disrupted mice below already diminished basal levels was unexpected. This outcome could be explained by the existence of passive repressors, which compete for the DNA binding site of a passive regulator. Many different reports suggest that AP-1 does not transactivate the ARE-mediated expression through ARE, but cJun, Jun D, Fra-1, and c-Fos are found in ARE bound nuclear proteins $(20,40)$. Among them, c-Fos and Fra1 were reported as down-regulating elements of ARE-mediated expression. Overexpression of c-Fos or Fra-1 repressed the expression of a hNQOl AREmediated reporter gene in HepG2 cells. Furthermore, disruption of c-Fos in vivo increased the basal activities of NQOI and GST in liver and kidney (41). These findings support a negative role of specific transcription factors in the expression of phase 2 enzymes. Induction of transcription factors C-Jun and Fra-l by $\beta \mathrm{NF}$ and t-butylated hydroquinone has been reported by several groups $(42,43)$. D3T treatment increases the levels of mRNA for c-Jun and c-Fos in mouse liver (unpublished observations). These transcription factors, some of which may be inducible by D3T, might bind to the ARE instead of Nrf2 and act as a passive repressor blocking the expression of phase 2 enzymes in $n r f 2$-deficient mice. The existence of negative regulating factors is further supported by the results of studies with cycloheximide in which treatment/pretreatment with cycloheximide increased the basal and inducible levels of GST Ya and MnSOD transcripts in wild-type mice (unpublished observations).

Overarching the effects of $n r f 2$ genotype on enzyme induction were the substantial effects of gender on the expression of GST and NQO1 activities. Constitutive activities of both enzymes were lower in the livers of female compared to male mice and induction of NQOl activity was only partially blocked in female mice compared to the complete abrogation observed in males of the nrf2-disrupted genotype. Montano et al $(44,45)$ have reported that estrogen 
receptors $\alpha$ and $\beta$ have binding affinity toward human NQO1 ARE and that anti-estrogens can induce NQO I expression via the estrogen receptor in breast cancer cell lines. Transactivation of the ARE by estrogen receptors may contribute to the observed gender differences in induction of phase 2 enzymes.

Because of the central role of $\mathrm{Nrf} 2$ in the inducible expression of many phase 2 enzymes in wild-type mice, the effects of D3T on hepatic Nrf2 expression and localization were examined in vivo. Nrf2 protein was found to rapidly accumulate within nuclei after D3T treatment. This rapid accumulation in nuclei results in increased binding activity of Nrf2 to ARE and presumably serves to enhance the expression of various phase 2 and antioxidative enzymes in vivo. It is unclear at this time whether the accumulation of Nrf2 in the nucleus represents translocation of $\mathrm{Nrf} 2$ from other sites in the cell or results from de novo synthesis of this transcription factor. Hepatic mRNA levels of Nrf2 were increased significantly by D3T treatment, and protein levels of Nrf2 in liver homogenates showed increases suggesting that one or both mechanisms for the observed increase remain possible. This increase in Nrf2 transcript was also observed with other phase 2 inducers, $\beta \mathrm{NF}$ and EQ. In contrast, Wild et al (40) reported that treatment of HepG2 cells with $\beta \mathrm{NF}$ or dithiocarbamate did not change the mRNA level of Nrf2 and suggested that post-transcriptional modulation could be a regulatory mechanism in the action of $\mathrm{Nrf2}$. About $1 \mathrm{~kb}$ of the promoter of $n r f 2$ has been reported and several SP-1 and AP-2 binding sites have been detected (46). AP-2 is known to be increased by oxidative stimuli such as UV-A (47) and DNA binding activity of AP-2 to its consensus sequence is modulated by redox status in vitro (48). D3T may react with proteins through redox mechanisms $(3,49)$. Thus, AP-2 may be an important transcription factor in the regulation of Nrf2 expression by D3T. Moreover, ARE (TGACTCCGC) or ARE-like (TGACTGTGGC) sequences are found in the 2502 and 2764 bp upstream region of murine Nrf2 (46). Levels of nuclear Nrf2 increase rapidly after D3T treatment such that increased Nrf2 within nuclei may act on these putative AREs of the Nrf2 promoter, thereby activating the expression of Nrf2. This type of autoregulation has been observed in the regulation of NF-kB activity. There are NF-kB regulating elements in the promoter of NF-kB and binding of nuclear NF-kB activates the transcription of NF-kB (50).

Another report suggests that anchoring proteins may affect the localization of Nrf2 within cells. The DNA binding activity of Nrf2 has been shown to be regulated by the cytoplasmic actin binding protein Keapl in vitro (51). Keapl binds to a conserved amino terminal domain of Nrf2 and acts as anchoring protein for Nrf2 in the cytoplasm. Keapl appears to impede the actions of Nrf2 on the ARE in quiescent cells. However, following exposure to electrophilic reagents such as $\mathrm{N}$-ethylmaleate, this binding of $\mathrm{Nrf2}$ to Keapl is altered and results in release of $\mathrm{Nrf2}$. Nrf2 appears to be translocated to nuclei. These findings suggest that Keapl or Nrf2 are functioning as sensor(s) to electrophilic and/or oxidant signals and interruption of the binding interactions between these two proteins could be an important factor in the regulation of the expression of phase 2 enzymes.

CNC-bZIP families such as a Nrf2 can dimerize with other bZIP proteins for reactions with ARE, and small Maf proteins or Jun/Fos proteins have been proposed as binding partners of $\operatorname{Nrf2}(20,27,40)$. Itoh et al (27) have shown that MafK can bind to MGST Ya ARE with Nrf2. Wild et al (40) detected binding of MafG and JunD to the ARE of the $\gamma$ GCS catalytic domain together with Nrf2. In the latter study, the level of MafG was induced by $\beta \mathrm{NF}$ and dithiocarbamate in HepG2 cells and this effect, together with increased DNA binding activity of $\mathrm{Nrf} 2$, were proposed as a mechanism of up-regulation of $\gamma \mathrm{GCSr}$ in vitro. Nguyen et al (52) reported that MafK/Nrf2 heterodimer interacts with ARE of GST and NQOI but the binding of MafK acts as a repressive regulator of ARE (52). It is likely that D3T affects the expression of these binding partners of Nrf2 to fully enhance AREmediated phase 2 gene expres-sion in vivo.

The central importance of Nrf2-regulated genes in protection against electrophile and oxidative toxicants emerged in several recent studies. Chan and Kan (53) have observed that $n r f 2$-deficient mice were considerably more sensitive to butylated hydroxytoluene-induced pulmonary injury than wild-type mice. Butylated hydroxytoluene is metabolically activated to reactive quinone methide derivatives, which are thought to mediate its cytotoxic action (54). Detoxification of butylated hydroxytoluene occurs primarily through glucuronidation, a pathway that may be diminished in the mutant mice. Recently Ishii et al (55) showed that peritoneal macrophages isolated from $n r f 2$-deficient mice showed impaired induction of stress protein A170, peroxiredoxin MSP23, and cysteine transport activity against electrophilic agents. Furthermore, these nrf2-deficient macrophages were more sensitive to electrophiles. Together with Nrf2, Nrf1 has binding activity to hNQOI ARE and is an important factor for cell survival in response to electrophilic agents (56). Disruption of $n r f 1$ is lethal in embryonic mice; however, fibroblast cells derived from $n r f 1$ null embryos can be shown to be sensitive to the toxicities of paraquat and cadmium chloride, which generate oxidative stress. In accord with these results, lack of expression of Nrf2 sensitizes the $n r f 2$ disrupted mice to pulmonary damage induced by hyperoxia (57). Collectively these studies show that CNC-bZIP proteins such as Nrf2 have critical functions in protective mechanism against environmental challenges. The direct involvement of Nrf2 in protection against carcinogenesis is under investigation in $n r f 2$-disrupted mice. 


\section{Acknowledgments}

We thank Dr. David Eaton for providing cDNA for mouse GST Yc, Patrick Dolan for maintaining and genotyping mice, and Julie Rider, Minerva RamosGomez, and Christopher Toscano for helpful discussions and assistance.

This work was supported by NIH Grants CA39416 and CA44530.

\section{References}

1. Wattenberg LW, Bueding E. (1986) Inhibitory effects of 5-(2-pyrazyinyl)-4-methyl-1,2-dithiol-3-thione (oltipraz) oncarcinogenesis induced by benzo[a]pyrene, diethylnitrosamine and uracil mustard. Carcinogenesis 7: 1379-1388.

2. Kensler W, Egner PA, Dolan P, Groopman JD, Roebuck BD. (1987) Mechanism of protection against aflatoxin tumorigenicity in rats fed 5-(2-pyrazyinyl)-4-methyl-1,2-dithiol-3thione (oltipraz) and related 1,2-dithiol-3-thiones and 1,2dithiol-3-ones. Cancer Res. 47: 4271-4277.

3. Kensler TW, Groopman JD, Sutter TR, Curphey TJ, Roebuck BD. (1999) Development of cancer chemopreventive agents: Oltipraz as a paradigm. Chem. Res. Toxicol. 12: 113-126.

4. Rushmore TH, King RG, Paulson KE, Pickett CB. (1990) Regulation of glutathione S-transferase Ya subunit gene expression: Identification of a unique xenobiotic-responsive element controlling inducible expression by planar aromatic compounds. Proc. Natl. Acad. Sci. U.S.A. 87: 3826-3830.

5. Friling RS, Bensimon A, Tichauer T, Daniel V. (1990) Xenobiotic-inducible expression of murine glutathione $S$ transferase Ya subunit gene is controlled by an electrophileresponsive element. Proc. Natl. Acad. Sci. U.S.A. 87: 6258-6262.

6. Okuda A, Imagawa M, Maeda Y, Sakai M, Muramatsu MJ. (1989) Structural and functional analysis of an enhancer GPEl having a phorbol 12-O-tetradecanoate-13-acetate responsive element-like sequence found in the rat glutathione transferase P gene. J. Biol. Chem. 264: 16919-16926.

7. Li Y, Jaiswal AK. (1992) Regulation of human NAD(P)H: quinone oxidoreductase gene: Role of AP-1 binding site contained within human antioxidant response element. J. Biol. Chem. 267: 15097-15104.

8. Favreau LV, Pickett CB. (1995) The rat quinone reductase antioxidant response element: Identification of the nucleotide sequence required for basal and inducible activity and detection of antioxidant response element-binding proteins in hepatoma and non-hepatoma cell lines. J. Biol. Chem. 270: 24468- 24474.

9. Primiano T, Gastel JA, Kensler TW, Sutter TR. (1996) Isolation of cDNAs representing dithiolthione-responsive genes. Carcinogenesis 17: 2297-2303.

10. Moinova HR, Mulcahy RT. (1998) An electrophile Responsive element (EpRE) regulation of $\beta$-naphthoflavone induction of the human $\gamma$-glutamylcysteine synthetase regulatory subunit gene; Constitutive expression is mediated by an adjacent AP-1 site. J. Biol. Chem. 273: 14683-14689, 1998.

11. Prestera T, Talalay P, Alam J, Ahn YI, Lee PJ, Choi AM. (1995) Parallel induction of heme oxygenase- 1 and chemoprotective phase 2 enzymes by electrophiles and antioxidants: Regulation by upstream antioxidant-responsive elements (ARE). Mol. Med. 1: 827-837.

12. Jaiswal AK. (1994) Antioxidant response element. Biochem. Pharmacol. 48: 439-444.

13. Friling RS, Bergelson S, Daniel V. (1992) Two adjacent AP-1like binding sites from the electrophile-response element of the murine glutathione S-transferase Ya subunit gene. Proc. Natl. Acad. Sci. U.S.A. 89: 668-672.

14. Xie T, Belinsky M, Xu Y, Jaiswal AK. (1995) ARE- and TREmediated regulation of gene expression: Response to xenobiotics and antioxidants. J. Biol. Chem. 270: 6894-6900.

15. Favreau LV and Pickett CB. (1993) Transcriptional regulation of the rat $\mathrm{NAD}(\mathrm{P}) \mathrm{H}$ quinone reductase gene: Characterization of a DNA-protein interaction of the antioxidant responsive element and induction by 12-O-tetradecanoylphorbol-13acetate. J. Biol. Chem. 268: 19875-19881.

16. Nguyen T, Rushmore TH, Pickett CB. (1994) Transcriptional regulation of rat liver glutathione $S$-transferase Ya subunit gene: Analysis of the antioxidant response element and its activation by the phorbol ester 12-O-tetradecanoylphorbol-13acetate. J. Biol. Chem. 269: 13656-13662.

17. Wang B, Williamson G. (1996) Transcriptional regulation of the human $\mathrm{NAD}(\mathrm{P}) \mathrm{Hquinone}$ oxidoreductase (NQO1) gene by monofunctional inducers. Biochim. Biophys. Acta. 1307: 104-110.

18. Wasserman WW, Fahl WE. (1997) Comprehensive analysis of proteins which interact with the antioxidant responsive element: Correlation of ARE-BP-1 with the chemoprotective induction response. Arch. Biochem. Biophys. 344: 387-396.

19. Wang B, Williamson G. (1994) Detection of nuclear protein which binds specifically to the antioxidant responsive element (ARE) of the human NAD(P)H:quinone oxidoreductase gene. Biochim. Biophys. Acta. 1219: 645-652.

20. Venugopal R, Jaiswal AK. (1996) Nrf1 and Nrf2 positively and c-Fos and Fral negatively regulate the human antioxidant response element-mediated expression of $\mathrm{NAD}(\mathrm{P}) \mathrm{H}$ : quinone oxidoreductasel gene. Proc. Natl. Acad. Sci. U.S.A. 93: 1496014965.

21. Andrews NC, Kotkow KJ, Ney PA, Erdjument-Bromage H, Tempst P, Orkin SH. (1993) The ubiquitous subunit of erythroid transcription factor NF-E2 is a small basic-leucine zipper protein related to the v-maf oncogene. Proc. Natl. Acad. Sci. U.S.A. 90: 11488-11492.

22. Igarashi $\mathrm{K}$, Itoh $\mathrm{K}$, Motohashi $\mathrm{H}$, et al. (1995) Activity and expression of murine small maf family protein MafK. J. Biol. Chem. 270: 7615-7624.

23. Chan JY, Han XL, Kan YW. (1993) Cloning of Nrfl, and NFE2-related transcription factor, by genetic selection in yeast. Proc. Natl. Acad. Sci. U.S.A. 90: 11371-11375.

24. Moi P, Chan K, Asunis I, Cao A, Kan YW. (1994) Isolation of NF-E2-related factor (Nrf2), a NF-E2-like basic leucine zipper transcriptional activator that binds to the tandem NF-E2/ AP-1 repeat of the $\beta$-globin locus control region. Proc. Natl. Acad. Sci. U.S.A. 91: 9926-9930.

25. Kobayashi A, Ito E, Toki T, et al. (1999) Molecular cloning and functional characterization of a new Cap'n Collar family transcription factor Nrf3. J. Biol. Chem. 274: 6443-6452.

26. Anrew NC, Erdjumant-Bromage H, Davidson MB, Tempst $P$, Orkin SH. (1993) Erythroid transcription factor NF-E2 is a haematopoietic-specific basic-leucine zipper protein. Nature 362: 722-728.

27. Itoh K, Chiba T, Takahashi S, et al. (1997) An Nrf2/small Maf heterodimer mediates the induction of phase II detoxifying enzyme gene through antioxidant response elements. Biochem. Biophys. Res. Commun. 236: 313-322.

28. Alam J, Stewart D, Touchard C, Boinapally S, Choi AMK, Cook JL. (1999) Nrf2, a Cap'n Collar transcription factor, regulates induction of the heme oxygenase-1 gene. J. Biol. Chem. 274: 26071-26078.

29. Egner PA, Kensler TW, Prestera T, et al. (1994) Regulation of phase 2 enzyme induction by oltipraz and other dithiolethiones. Carcinogenesis 15: 177-181.

30. Buetler TM, Eaton DL. (1992) Complementary DNA cloning, messenger RNA expression, and induction of $\alpha$-class glutathione $S$-transferase in mouse tissues. Cancer Res. 52: 314-318.

31. Prochaska HJ, Santamaria AB, Talalay P. (1992) Rapid detection of inducers of enzymes that protect against carcinogens. Proc. Natl. Acad. Sci. U.S.A. 89: 2394-2398.

32. Habig WH, Pabst MJ, Jakoby WB. (1974) Glutathione $S$-transferases. The first enzymatic step in mercapturic acid formation. J. Biol. Chem. 219: 7130-7139.

33. Chomczynski P, Sacchi N. (1987) Single-step method of RNA isolation by acid guanidinium thiocyanate-phenol-chloroform extraction. Anal. Biochem. 162: 156-159.

34. Kim ND, Kwak MK, Kim SG. (1997) Inhibition of cytochrome P-450 2El expression by 2-(allylthio)pyrazine, a 
potential chemoprotective agent: Hepatoprotective effects. Biochem. Pharmacol. 53: 261-269.

35. Dignam JD, Lebovitz RM, Roeder RG. (1983) Accurate transcription initiation by RNA polymerase II in a soluble extract from isolated mammalian nuclei. Nucleic Acids Res. 11: 1475-1489.

36. Otieno MA, Kensler TW, Guyton KZ.(2000) Chemoprotective $3 \mathrm{H}$-1,2-dithiole-3-thione induces antioxidant genes in vivo. Free Radic. Biol. Med. 28: 944-952.

37. Buetler TM, Gallagher EP, Wang C, Stahl DL, Hayes JD, Eaton DL. (1995) Induction of phase I and phase II drugmetabolizing enzyme mRNA, protein, and activity by BHA, ethoxyquin, and oltipraz. Toxico. Appl. Pharmacol. 135: $45-57$.

38. Knight LP, Primiano T, Groopman JD, Kensler TW, Sutter TR. (1999) cDNA cloning, expression and activity of a second human aflatoxin $B_{1}$-metabolizing member of the aldo-keto reductase superfamily, AKR7A3. Carcinogenesis 20: 101-108.

39. Monroe DH, Eaton DL. (1987) Comparative effects of butylated hydroxyanisole on hepatic in vivo DNA binding and in vitro biotransformation of aflatoxin $\mathrm{B}_{1}$ in the rat and mouse. Toxicol. Appl. Pharmacol. 90: 401-409.

40. Wild AC, Moinova HR, Mulcahy RT. (1999) Regulation of $\gamma$ glutamylcysteine synthetase subunit gene expression by the transcription factor Nrf2. J. Biol. Chem. 274: 33627-33636.

41. Wilkinson J, Venugopal Radjendirane IV, Pfeiffer GR, Jaiswal AK, Clapper ML. (1998) Disruption of c-Fos leads to increased expression of $\mathrm{NAD}(\mathrm{P}) \mathrm{H}$ :quinone oxidoreductase 1 and glutathione $S$-transferase. Biochem. Biophys. Res. Commun. 253: 855-858.

42. Yoshioka K, Deng T, Cavigelli M, Karin M. (1995) Antitumor promotion by phenolic antioxidants: Inhibition of AP-1 activity through induction of Fra expression. Proc. Natl. Acad. Sci. U.S.A. 92: 4972-4976.

43. Wild AC, Gipp JJ, Mulcahy T. (1998) Overlapping antioxidant response element and PMA response element sequences mediate basal and beta-naphthoflavone-induced expression of the human gamma-glutamylcysteine synthetase catalytic subunit gene. Biochem. J. 332: 373-381.

44. Montano M, Katzenellenbogen BS. (1997) The quinone reductase gene: A unique estrogen receptor-regulated gene that is activated by antiestrogens. Proc. Natl. Acad. Sci. U.S.A. 94: 2581-2586.

45. Montano M, Jaiswal AK, Katzenellenbogen BS. (1998) Transcriptional regulation of the human quinone reductase gene by antiestrogen-liganded estrogen receptor- $\alpha$ and estrogen receptor- $\beta$. J. Biol. Chem. 273: 25443-25449.

46. Chan K, Lu R, Chang JC, Kan YW. (1996) NRF2, a member of the NFE2 family of transcription factors, is not essential for murine erythropoiesis, growth, and development. Proc. Natl. Acad. Sci. U.S.A. 93: 13943-13948.

47. Dalton TP, Shertzer HG, Puga A. (1999) Regulation of gene expression by reactive oxygen. Annu. Rev. Pharmacol. Toxicol. 39: $67-101$.

48. Huang Y, Domann FE. (1998) Redox modulation of AP-2 DNA binding activity in vitro. Biochem. Biophys. Res. Commun. 249: 307-312.

49. Kim W, Gates KS. (1997) Evidence for thiole-dependent production of oxygen radicals by 4-mrthyl-5-pyrazinyl-3H-1, 2-dithiole-3-thione (oltipraz) and 3H-1,2-dithiole-3-thione: Possible relevance to the anticarcinogenic properties of 1,2dithiole-3-thiones. Chem. Res. Toxicol. 10: 296-301.

50. Liptay S, Schmid RM, Nabel EG, Nabel GJ. (1994) Transcriptional regulation of NF-kappa B2: Evidence for kappa B-mediated positive and negative autoregulation. Mol. Cell Biol. 14: 7695-7703.

51. Itoh K, Wakabayashi N, Katoh Y, et al. (1999) Keapl represses nuclear activation of antioxidant responsive elements by Nrf2 through binding to the amino-terminal Neh2 domain. Genes Dev. 13: 76-86.

52. Nguyen T, Huang HC, Pickett CB. (2000) Transcriptional regulation of the antioxidant response element: Activation by Nrf2 and repression by MafK. J. Biol. Chem. 275: 15466-15473.

53. Chan K, Kan YW. (1999) Nrf2 is essential for protection against acute pulmonary injury in mice. Proc. Natl. Acad. Sci. U.S.A. 96: 12731-12736.

54. Guyton KZ, Thompson JA, Kensler TW. (1993) Role of quinone methide in the in vitro toxicity of the skin tumor promoter butylated hydroxytoluene hydroperoxide. Chem. Res. Toxicol. 6: 731-738.

55. Ishii T, Itoh K, Takahashi S, et al. (2000) Transcription factor Nrf2 coordinately regulates a group of oxidative stressinduced genes in macrophages. J. Biol. Chem. 275: 16023-16029.

56. Kwong M, Kan YW, Chan JY. (1999) The CNC basic leucine zipper factor, Nrfl, is essential for cell survival in response to oxidative stress-inducing agents. J. Biol. Chem. 274: 37491-37498.

57. Cho H-Y, Reddy SPM, Zhang LY, et al. Quantitative trait locus analysis of hyperoxic lung injury in mice and the role of Nrf2 as a candidate susceptibility gene (Submitted). 